\title{
Evolução holocênica das encostas da bacia do riacho Bruscas, Nordeste do Brasil
}

\section{Holocenic hillslope evolution of Bruscas creek watershed, Northeast of Brazil}

\author{
Rodrigo de Freitas Amorim ${ }^{1 *} \bowtie(D)$, Antonio Carlos de Barros Corrêa $₫$ (iD), Demétrio \\ Mutzenberg $^{3} \bowtie$, Débora Albuquerque Meira $4 \bowtie$ \\ 1Departamento de Geografia, Centro de Ciências Humanas, Letras e Artes, \\ Universidade Federal do Rio Grande do Norte, Natal, Rio Grande do Norte, Brasil \\ 2 Departamento de Geografia, Universidade Federal de Pernambuco, Recife, Pernambuco, Brasil \\ 3Departamento de Arqueologia, Universidade Federal de Pernambuco, Recife, Pernambuco, \\ Brasil \\ 4Doutora em Geografia pela Universidade Federal de Pernambuco, Recife, Pernambuco, Brasil \\ E-mails: dbiase2001@terra.com.br (ACBC); demutzen@gmail.com (DM); \\ debora_mmeira@hotmail.com (DAM) \\ *E-mail para correspondência: rodrigofba@gmail.com
} Recebido (Received): 30/04/2019

\begin{abstract}
Resumo: Localizada na Província Geológica da Borborema, a bacia do Riacho Bruscas constitui importante amostra do contexto geomorfológico e geológico do setor oriental do Nordeste do Brasil, onde a morfogênese e suas implicações paleoclimáticas são particularmente distintas daquelas que afetam áreas do sul e sudeste do país. O presente trabalho tem como objetivo analisar encostas com coberturas coluviais da bacia do Riacho Bruscas, tomando como base as características dos sedimentos, sua cronologia absoluta (LOE), geometria, estrutura e arranjo estratigráfico. Apesar de fragmentários, disjuntos espacialmente, e originários de intensidades distintas, esses materiais podem fornecer informações importantes sobre a dinâmica geomorfológica que, em última instância, reflete a ação dos componentes paleoambientais sobre a organização das unidades agradacionais do relevo. Os resultados foram agrupados em função dos dados coletados em quatros setores distintos da bacia, onde ocorrem depósitos coluviais, de forma a abranger todos os contextos morfológicos que, na área, resultaram na acumulação de sedimentos de encosta. Os depósitos estudados apresentaram-se confinados em intervalo de tempo que alcança desde o limiar Pleistoceno/Holoceno até a Pequena Idade do Gelo. Contudo, enquanto os depósitos resultantes da reumidificação geral observada ao final do Pleistoceno são ubíquos nas demais áreas do Nordeste semiárido, os depósitos do Holoceno médio e superior apontam para ocorrências mais localizadas, provavelmente relacionadas à ação de eventos pluviais orograficamente condicionados, mais intensos sobre o maciço da Serra da Baixa Verde e outros setores elevados do Planalto da Borborema.
\end{abstract}

Palavras-chave: Informações paleoambientais; modelados agradacionais; depósitos de encosta.

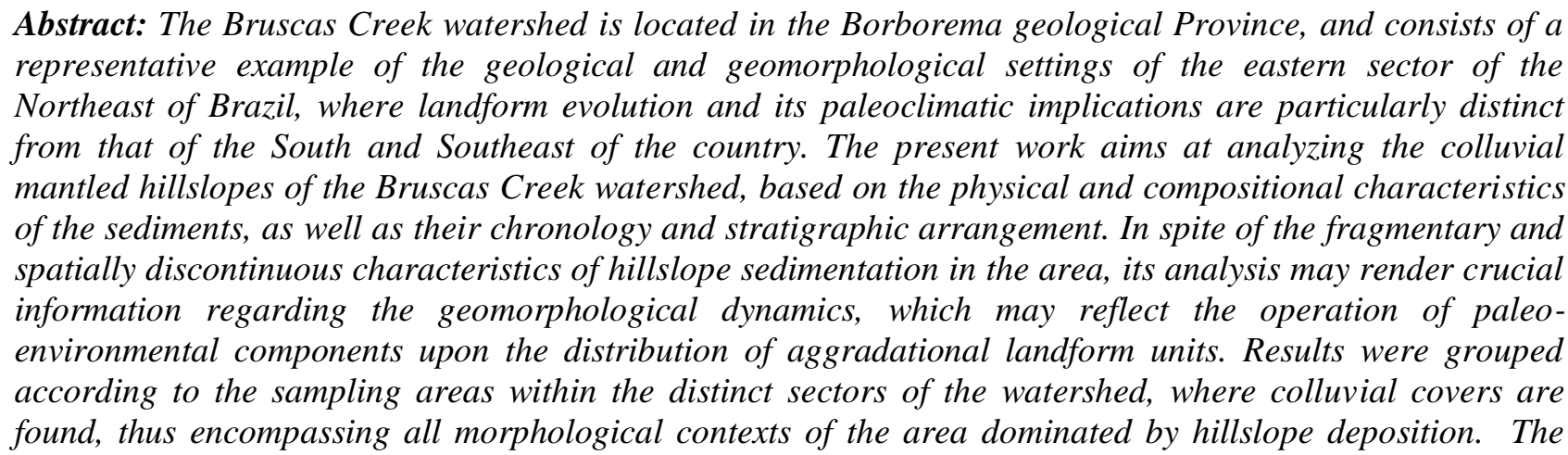


analyzed sediments were confined to a timeframe ranging from the Pleistocene/Holocene threshold to Little Ice Age. Nonetheless, whereas deposits resulting from the overall re-humidification of the Late Pleistocene are ubiquitous in other areas of the semi-arid Northeast, mid-and Upper Holocene colluviation points to the occurrence of rather localized rainfall events, possibly related to the orographic control exerted by the Baixa Verde massif and other elevated sectors of the Borborema Highlands.

Keywords: Paleoenvironmental data; aggradational landforms; hillslope deposition.

\section{Introdução}

Cada região morfogenética apresenta características evolutivas distintas em suas encostas, demandando entendimento dos gatilhos de mudanças dentro dos intervalos de tempo compatíveis com o contexto analisado. As taxas de alterações nas encostas e a definição das escalas temporais de sua dinâmica evolutiva são amplas e complexas, podendo coexistir diferentes intensidades de processos em um mesmo compartimento do relevo, exigindo o reconhecimento das variáveis e propriedades em cada caso (SELBY, 1993; LANCI; HIRT 2015; AMORIM et al., 2015).

É nos momentos de histerese do sistema que há movimentação de sedimento nas encostas e formação de depósitos de encostas, os colúvios, sendo que em áreas tectonicamente estáveis os gatilhos geomorfológicos são geralmente de ordem climática ou antrópica. Os colúvios representam um dos principais registros de mudanças paleoclimáticas para o estudo do Holoceno, ao mesmo tempo que compreendem um compartimento do relevo no trânsito de sedimentos entre as porções mais elevadas e os fundos de vale (CORRÊA, 2001; THOMAS, 2004, PAISANI et al., 2017).

As oscilações climáticas no Holoceno demostram uma instabilidade na escala de milhares de anos muito maior do que a aparente estabilidade do período interestadial, tendo na região tropical os colúvios, com suas estruturas deposicionais peculiares, como um dos proxies mais relevantes para entender as a dinâmica climáticas nos trópicos, especialmente no que tange a variação de intensidade e posicionamento da Zona de Convergência Intertropical (ZCIT). Por exemplo, na única área tropical semiárida da fachada atlântica do continente sulamericano, os fatores responsáveis pela morfogênese e suas implicações paleoclimáticas são particularmente distintos daqueles que afetam as áreas do sul e sudeste do Brasil, cujos elementos desencadeadores já foram enunciados em diferentes contextos de reconstrução paleoambiental (MOURA; MELLO, 1991; MOURA et al., 1998; BEHLING; LICHETE, 1997), evidenciando a ação mais eminente de sistemas atmosféricos extra-tropicais sobre a gênese modelado.

Neste panorama, passa a ser imperativo a reconstrução dos processos superficiais estruturadores da paisagem, buscando definir intervalos cronológicos que reflitam de forma mais realista a ação formativa dos agentes geomorfológicos sobre a hierarquização dos componentes da paisagem. Para tanto, é preciso identificar as unidades do relevo que guardam as informações paleoambientais, assim como entender o controle dos gatilhos desencadeadores de processos esculturadores e deposicionais. Por fim, de posse dessas informações criar modelos interpretativos, com base na premissa de que os dados geocronológicos e suas expressões superficiais derivadas se aninham em diferentes escalas de espaço e tempo.

Diante do exposto, a análise proposta neste trabalho está centrada na premissa de que as características dos sedimentos, granulometria, sua natureza química, cronologia absoluta, geometria, estrutura e arranjo estratigráfico são remanescentes de processos pretéritos, que apesar de fragmentários e disjuntos espacialmente, e atuando sob intensidades distintas, podem fornecer informações importantes sobre a dinâmica geomorfológica que, em última instância, reflete a ação dos componentes paleoambientais sobre a organização das unidades agradacionais do relevo.

\subsection{Localização da área de estudo}

Localizada na Província Geológica da Borborema, a bacia do Riacho Bruscas constitui uma importante amostra do contexto geomorfológico e geológico do setor oriental do Nordeste do Brasil (Figura 1), sendo a bacia uma amostra para o entendimento da evolução da paisagem desse setor. As transformações geomorfológicas ocorridas ao longo do Quaternário e, sobretudo, no Pleistoceno Superior e Holoceno são ainda muito pouco conhecidas para o setor semiárido do Nordeste do Brasil, e, portanto, essa pesquisa somase a um número de trabalhos que busca compreender as diferenças intra-regionais da morfogênese no Nordeste semiárido ao longo do Quaternário superior. 
A bacia do Riacho Bruscas constitui uma bacia de primeira ordem com cabeceiras não canalizadas, sobre um maciço sienítico neo-proterozóico, inserido na escarpa ocidental do principal compartimento geomorfológico do Nordeste oriental do Brasil, o Planalto da Borborema; uma intumescência regional majoritariamente alicerçada em rochas metamórficas e plutônicas meso- e neo-proterozóicas. Em razão da variação altimétrica entre nascentes e desembocadura, ocorre na área uma zonação altitudinal climática (AMORIM, 2015), de semiárido na foz a subúmido na superfície de cimeira, com presença de mantos de intemperismo mais espessos sobre essa última, remobilizados à jusante sob a forma de modelados agradacionais, especificamente encostas com cobertura coluvial e alúvio-coluvial.

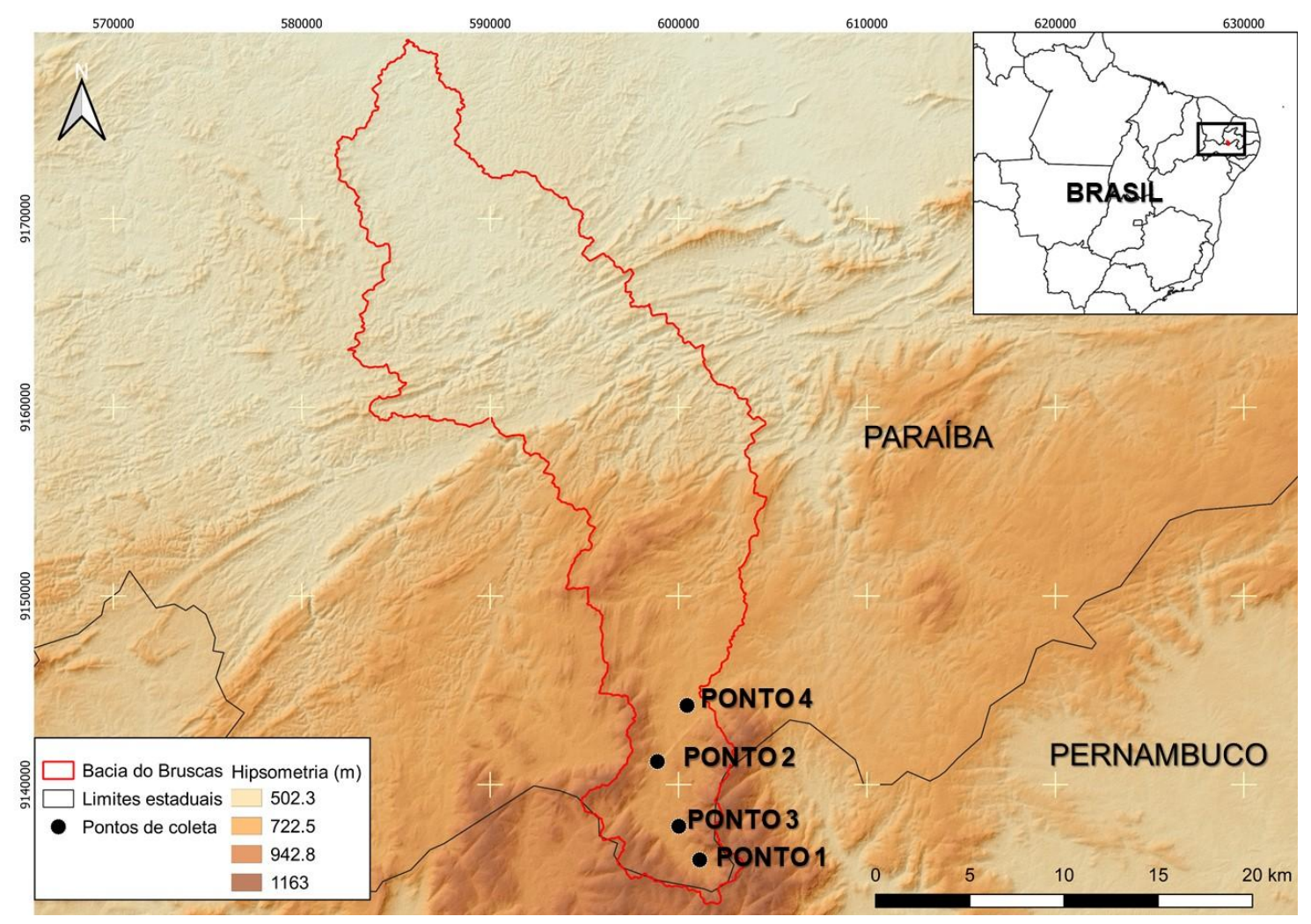

Figura 1: Localização da Área de estudo.

\section{Metodologia}

O trabalho foi baseado na aplicação de técnicas morfoestratigráficas (análise das estruturas deposicionais dos colúvios e sua relação com as formas agradacionais), sedimentológicas (análise granulométrica e grau de arredondamento dos grãos) e geocronológica (Luminescência Opticamente Estimulada) em sedimentos de encosta da porção elevada da Bacia do Riacho Bruscas, estabelecendo a sequência de eventos deposicionais, responsáveis pelo desenvolvimento de formas de agradação na paisagem, no caso, rampas de colúvio. Outra premissa norteadora da metodologia adotada recai na ideia de que os sedimentos coluviais em tela são essencialmente climato-sensitíveis, como sugere Thomas (2004) para a maior parte das terras baixas tropicais do globo, em especial sobre áreas plataformais.

A análise dos parâmetros granulométricos foi utilizada para compreensão do fluido transportador de sedimentos, velocidade, grau de turbulência. Os parâmetros estatísticos (assimetria e curtose) permitiram estabelecer a relação entre os processos e os produtos para os sedimentos, onde o transporte promove uma seleção que caracteriza o deposito sedimentar (CAMARGO FILHO; BIGARELLA, 1998).

Os valores de assimetria muito positiva estão relacionados às fácies areno-argilosas e muito negativa àquelas argilo-arenosas e argilo-sílticas (BIGARELLA et al., 1975). Por sua vez, a determinação do grau de arredondamento, esfericidade e mineralogia dos grãos foi executada através da análise morfoscópica tradicional por lupa binocular, caracterizando qualitativamente e quantitativamente o material, de forma a reconstruir a dinâmica deposicional, e o material residual que deu origem aos depósitos.

Para identificação da cronologia dos sedimentos foi utilizado o método da luminescência opticamente estimulada, o qual compreende o conjunto de técnicas cujo objetivo é medir a carga radioativa acumulada em armadilhas cristalinas, após a carga anterior ter sido zerada pela radiação solar, em grãos de quartzo e feldspato, resultante do decaimento de materiais radioativos existentes no depósito sedimentar, sendo viável 
para intervalos de tempo entre $10^{2}$ a $10^{6}$ anos, fornecendo o tempo de fechamento da camada sedimentar estudada (AITKEN, 1998).

Em campo, após identificadas as seções estratigráficas representativas de cada ponto de coleta, foram amostrados níveis que refletissem dentro de cada coluna possíveis rupturas no processo deposicional, assim separando unidades em função do evento formador. As amostras foram coletadas utilizando tubos de PVC pretos, através da introdução à percussão dos tubos, de forma perpendicular à face da trincheira de coleta. Em seguida, as amostras foram lacradas sem exposição ao sol e enviadas para serem datadas no Laboratório de datação, comércio e prestação de serviços LTDA., utilizando o protocolo SARs com 15 Alíquotas, sendo as leituras realizadas em grãos de Feldspato.

No tocante à construção das sessões verticais, executou-se a acoplagem da litofáceis com a geocronologia $\mathrm{e}$, indiretamente, o desvio de paleotemperatura oriunda dos dados para o hemisfério sul definidos por PETIT et al. (1999).

\section{Resultados e discussões}

Os resultados foram agrupados em função dos dados coletados em quatros setores distintos da bacia, onde ocorrem depósitos coluviais, de forma a abranger todos contextos morfológicos que resultaram na acumulação de sedimentos de encosta. A correlação temporal entre os diversos depósitos analisados permitiu aventar hipóteses sobre sua gênese, estabelecendo se a mesma esteve atrelada a eventos formativos em escala regional, ou se refletiam episódios deposicionais de âmbito local, quando comparados com dados já existentes na literatura.

Apesar da faixa de erro obtida oscilar em torno de $<20 \%$ por amostra (Tabela 1), a falta de marcadores cronoestratigráficos para o Quaternário da região permite a utilização desses dados com certa confiança, sobretudo quando comparados a outros trabalhos recentes que utilizaram o mesmo protocolo de datação para sedimentos de encosta no maciço da Baixa Verde (CORRÊA, 2009; TAVARES, 2015). Nestes casos é notável a concentração de idades holocênicas, com poucas ocorrências relativas à transição Pleistoceno/Holoceno (Younger Dryas?) ou ao Último máximo glacial.

Tabela 1: Idades das amostras e informações da datação por LOE

\begin{tabular}{|c|c|c|c|c|c|c|c|c|}
\hline Código & Th & $\mathbf{U}$ & $\mathbf{K}$ & $\begin{array}{c}\text { Dose Anual } \\
(\mu G y / a n o)\end{array}$ & $\mathbf{P}(\mathbf{G y})$ & $\begin{array}{l}\text { Desvio } \\
\text { padrão }\end{array}$ & Idade & Erro \\
\hline A1 & 9,820 & 4,462 & 9,181 & $11.400 \pm$ & & & 1.87 & \\
\hline $410 \mathrm{~cm}$ & $\pm 0,354$ & $\pm 0,350$ & $\pm 1,331$ & 1.480 & 21,4 & 4,4 & 0 & \pm 330 \\
\hline A1 & 10,131 & 3,963 & 7,941 & $9.900 \pm$ & & & 4.70 & \\
\hline $380 \mathrm{~cm}$ & $\pm 0,365$ & $\pm 0,486$ & $\pm 1,151$ & 1.330 & 46,4 & 13,3 & 0 & \pm 860 \\
\hline A1 & 9,517 & 4,230 & 7,931 & $9.950 \pm$ & & & 4.75 & \\
\hline $230 \mathrm{~cm}$ & $\pm 0,343$ & $\pm 0,356$ & $\pm 1,150$ & 1.300 & 47,2 & 10,6 & 0 & \pm 860 \\
\hline A1 & 9,792 & 3,415 & 7,753 & $9.500 \pm$ & & & 6.30 & \\
\hline $153 \mathrm{~cm}$ & $\pm 0,353$ & $\pm 0,180$ & $\pm 1,124$ & 1.200 & 60,6 & 7,6 & 0 & \pm 1.130 \\
\hline A2 & 17,849 & 5,597 & 8,618 & $11.600 \pm$ & & & & \\
\hline $89 \mathrm{~cm}$ & $\pm 0,643$ & $\pm 0,586$ & $\pm 1,250$ & 1.480 & 5,4 & 1,2 & 465 & \pm 80 \\
\hline A2 & 13,124 & 4,001 & 6,346 & $8.500 \pm$ & & & 2.30 & \\
\hline $40 \mathrm{~cm}$ & $\pm 0,472$ & \pm 0492 & $\pm 0,920$ & 1.100 & 19,3 & 2,5 & 0 & \pm 410 \\
\hline A3 & 10,576 & 3,417 & 6,308 & $8.150 \pm$ & & & 5.30 & \\
\hline $230 \mathrm{~cm}$ & $\pm 0,381$ & $\pm 0,020$ & $\pm 0,915$ & 970 & 42,6 & 7,5 & 0 & \pm 880 \\
\hline A3 & 10,845 & 4,193 & 7,269 & $9.330 \pm$ & & & 5.70 & \\
\hline $123 \mathrm{~cm}$ & $\pm 0,389$ & $\pm 0,592$ & $\pm 1,054$ & 1.260 & 53,1 & 10,5 & 0 & \pm 1.050 \\
\hline A3 & 10,582 & 3,191 & 7,742 & $9.500 \pm$ & & & 11.7 & \\
\hline $10 \mathrm{~cm}$ & $\pm 0,381$ & $\pm 0,119$ & $\pm 1,123$ & 1.200 & 112 & 24,2 & 00 & \pm 2.060 \\
\hline A4 & 14,987 & 3,432 & 4,386 & $6.600 \pm$ & & & & \\
\hline $65 \mathrm{~cm}$ & $\pm 0,540$ & $\pm 0,400$ & $\pm 0,636$ & 800 & 3,5 & 0,72 & 530 & \pm 90 \\
\hline A4 & 16,440 & 4,848 & 5,315 & $8.000 \pm$ & & & 2.00 & \\
\hline $35 \mathrm{~cm}$ & $\pm 0,592$ & $\pm 0,178$ & $\pm 0,771$ & 880 & 15,5 & 1,37 & 0 & \pm 300 \\
\hline
\end{tabular}

\section{1. Área 01}

A área está localizada nas proximidades da nascente do Riacho Bruscas, formada por um leque coluvial, a $808 \mathrm{~m}$ de altitude, seccionado por uma voçoroca de orientação NE-SW com profundidade variando de 30 
centímetros a 06 metros. Do topo à base a encosta tem $1.300 \mathrm{~m}$ de comprimento, com declividade média de 20,6\% (Figura 2).

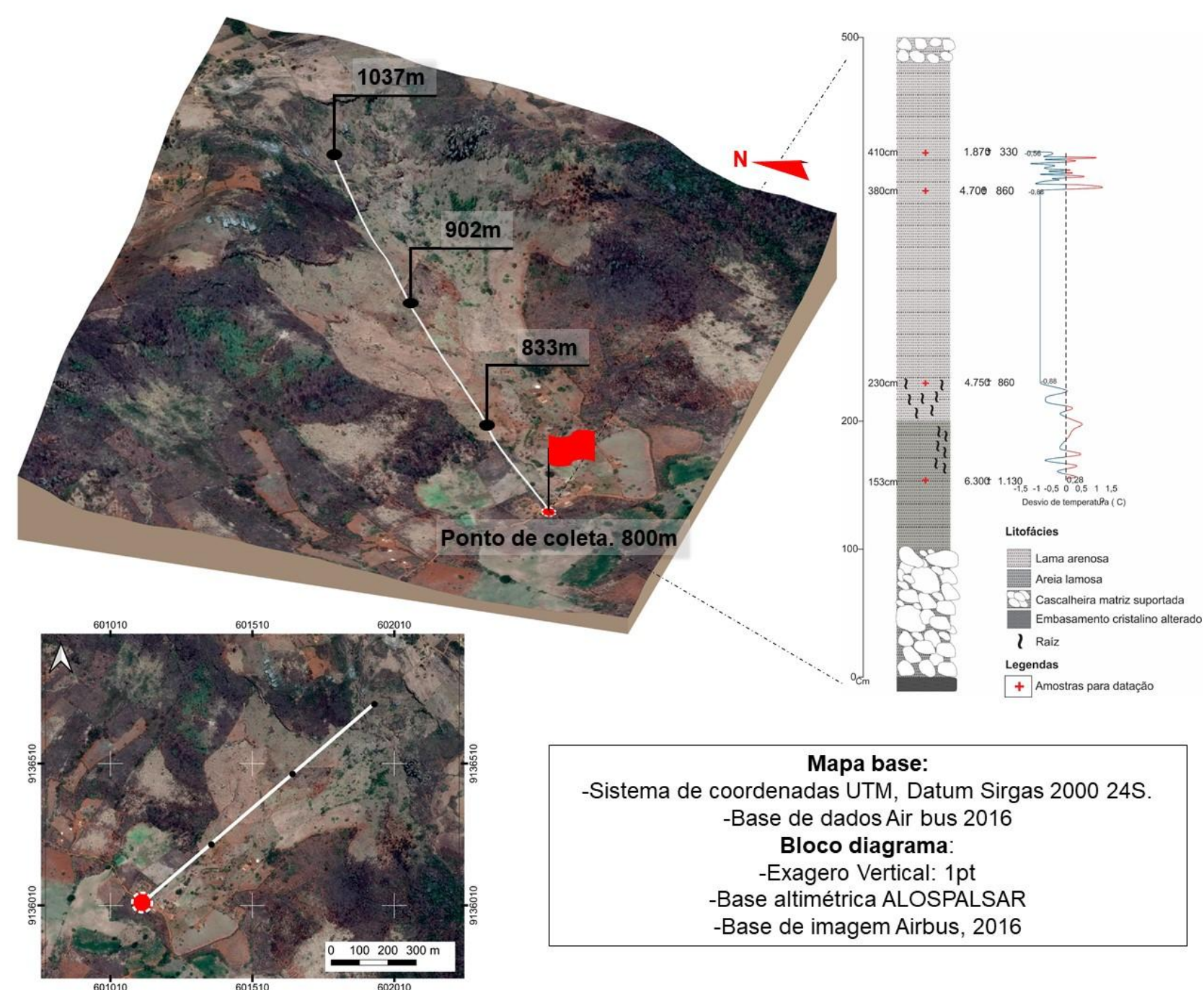

Figura 2: Bloco diagrama mostrando um leque coluvial com indicativo de altitudes e localização do ponto de coleta, perfil vertical do material amostrado e indicação das idades e os desvios de paleotemperatura para cada idade. Fontes: dados de paleotemperatura modificados de Petit et al., (1999), sedimentológicos de Ramos (2014).

O material coluvial caracteriza-se como areia média com grânulos, com exceção do topo que apresentou uma cascalheira matriz suportada, estando depositada sobre uma cascalheira basal localizada imediatamente acima do embasamento cristalino (Figura 3). A granulometria do depósito, lama arenosa e areia lamosa, refletiu a predominância do intemperismo químico e amadurecimento mineralógico na formação do material parental, oriundo dos setores superiores da encosta. Processos superficiais de corrida de lama, com hidrodinâmica alta (torrentes não canalizadas), atuaram no retrabalhamento do material, com a remobilização do regolito em profundidade e fluxo de detritos no topo.

Todas as amostras do perfil apresentaram-se pobremente selecionadas. Nas profundidades de $153 \mathrm{~cm}$, $308 \mathrm{~cm}$ e $410 \mathrm{~cm}$ a assimetria muito negativa indica transporte bidirecional, com ação de mais de um fluxo de atuação em momentos e intensidades distintas. A profundidade de $230 \mathrm{~cm}$ apresentou assimetria positiva indicando fluxo unidirecional, o qual restringe o limite superior do tamanho dos grãos transportados mais grossos e uma cauda de grãos mais finos (CAMARGO FILHO; BIGARELLA, 1998).

Os sedimentos estudados são pouco agregados e morfologicamente heterogêneos, com predomínio do padrão sub-discoidal nos horizontes superiores e esférico no nível de $230 \mathrm{~cm}$ abaixo da superfície, com $80 \%$ dos grãos analisados nesta classe morfoscópica. Tais características corroboram a prevalência das corridas de lama a curta distância como principal processo envolvido na deposição dos sedimentos; com pouca alteração das morfologias originais dos grãos. 
A presença de minerais do ciclo supérgeno, como as concreções ferruginosas, apontam para a ocorrência de pedorelíquias nos depósitos coluviais da região (CORRÊA, 2001), herdadas do desmantelamento de antigas crostas lateríticas cujos fragmentos, espacialmente disjuntos e pouco espessos, ainda recobrem trechos dos topos dos divisores que integram os níveis somitais do Maciço. Segundo Tavares (2015) a presença ubíqua dessas heranças pedológicas por sobre a cimeira da Serra da Baixa Verde, provavelmente remonta a fases climáticas mais úmidas pré-quaternárias.

As idades dos sedimentos que integram o leque coluvial da Área 01, apontam para ocorrência de períodos de maior torrencialidade entre 6.300 e 1.870 anos A.P. O nível estratigráfico mais antigo é correlato ao momento de incremento das chuvas, como observado em outros setores do Nordeste Oriental e do próprio Maciço da Serra da Baixa Verde (CORRÊA, 2001), que resultou em coluvionamento extensivo sobretudo nos níveis topográficos mais elevados do Planalto da Borborema, e remoção dos mantos de intemperismo que ainda recobriam as cimeiras à montante das rampas.

Eventos de formação de colúvios por deposição de fluxos gravitacionais foram ainda estudados por Lira (2015) no sub-médio São Francisco, a 300km a sudoeste do Maciço da Serra da Baixa Verde. Neste caso o autor encontrou a idade de 6.180 A.P. para os fluxos de detritos, referidos, portanto, ao hipsitermal ou optimum climático do Holoceno médio. Ainda mais a oeste da área de estudo, na Serra da Capivara-PI, Mutzenberg (2010) identificou leques aluviais datados de 6.200 anos A.P.; o que corrobora a ocorrência de fase mais úmida cuja abrangência abarcara todo o core semiárido do Nordeste brasileiro. Reforçando esta perspectiva, o estudo de Silva (2013), em setores do Planalto da Borborema situados a mais de $200 \mathrm{~km} \mathrm{a}$ leste do Riacho Bruscas, igualmente revelou a ocorrência de uma fase de deposição de fluxos de detritos nas encostas graníticas do Brejo da Madre de Deus-PE datada de 6.350 \pm 890 .

Dados locais (CORREAA, 2001; TAVARES, 2015) e regionais apontam para que a fase úmida do holoceno médio pode haver se estendido até mais tardiamente, como sugerem os níveis estratigráficos datados neste trabalho de $4.750 \pm 860$ e $4.700 \pm 860$ A.P. Neste sentido, Gurgel et al. (2013) encontraram

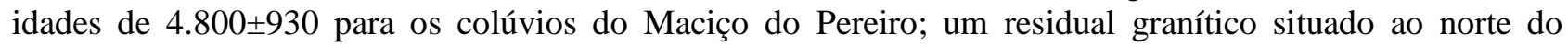
Planalto da Borborema, no extremo sudoeste do Rio Grande do Norte. O fato desta idade se repetir para a deposição de colúvios em diversos contextos planálticos do Nordeste oriental aponta para a provável ocorrência de um evento climático de abrangência regional por volta de 4.700 A.P. Globalmente este período coincide com uma fase de elevação da temperatura associada à fase final do Younger Dryas. A esse momento, no contexto da América do Sul, corresponderia a ocorrência de uma fase fria do Paleo-ENOS, com deslocamento da Célula de Walker para oeste e condições atmosféricas mais propícias à convecção no semiárido nordestino (CONROY et al., 2008; STAINES-URÍAS et al., 2015).

Ao contrário das unidades estratigráficas datadas do Holoceno médio por Corrêa (2001) e Tavares (2015), esses autores não identificaram colúvios mais recentes (Holoceno superior) na área de estudo. Desta forma as idades de $1.870 \pm 330$ A.P. e $2.000 \pm 300$ a. A.P. obtidas para corridas de lama por esta pesquisa constituem um dado inédito, cronocorrelato aos depósitos de encostas de $1.730 \pm 280$ e $1.950 \pm 175$ A.P. encontrados por Gurgel et al. (2013) para o Maciço do Pereiro no sudoeste do Rio Grande do Norte.

Imediatamente após essa última fase provavelmente mais torrencial do Holoceno superior, Lira (2014) constatou a ocorrência de episódios de reativação eólica nos campos de dunas do sub-médio São Francisco em Petrolina-PE, datados de $1.700 \pm 230$ anos A.P. A retomada de condições de secura na região coincide com a falta de sedimentação de encosta na área de estudo até aproximadamente 700 anos A.P.

Globalmente, este período coincide com intervalo entre eventos do tipo Bond, com significativa redução da temperatura da ordem de $-1,24^{\circ} \mathrm{C}$ (PETIT et al., 1999). Para a América do Sul observa-se também a ocorrência de uma forte fase fria do Paleo-ENOS (MOY et al., 2002; CONROY et al., 2008).

\section{2. Área 02}

Compreende leque alúvio-coluvial, inserido em alvéolo em forma de anfiteatro aberto, dissecado pela drenagem, na base de uma encosta com $766 \mathrm{~m}$ de comprimento e 32,9\% de declividade média (Figura 3). A estratigrafia do depósito é constituída de cascalheira fluvial na base, ocorrendo camada maciça de lamito sem estratificação até a profundidade de $60 \mathrm{~cm}$, onde ocorre carvão vegetal disperso na matriz. A camada do topo é formada por estratificação plano-paralela, resultado de sucessivos processos laminares de deposição, evidenciando momento de maior estabilidade climática. 


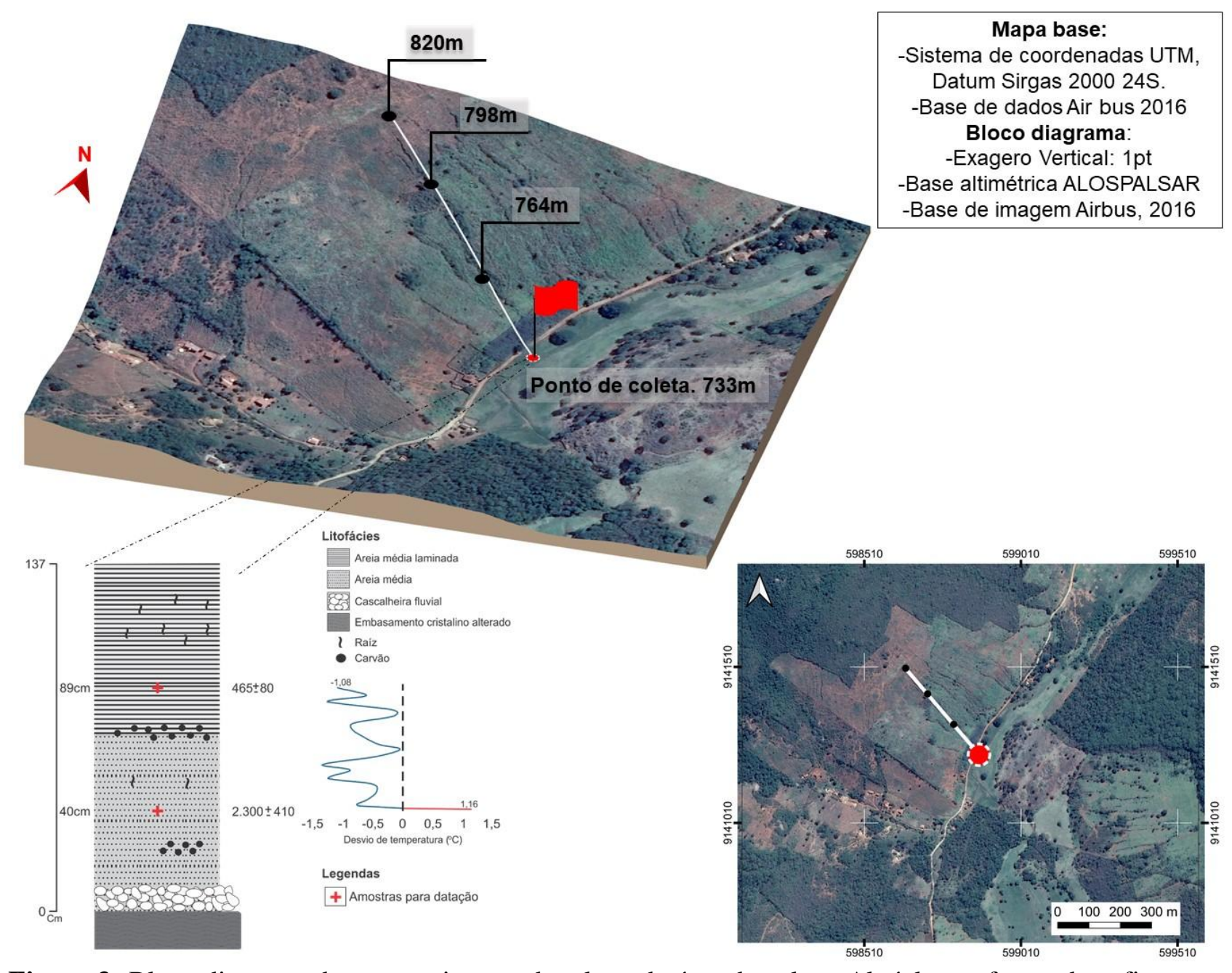

Figura 3: Bloco diagrama do compartimento de relevo da área de coleta. Alvéolo em forma de anfiteatro, com indicação das idades e os desvios de paleotemperatura para cada idade. Fontes: dados de paleotemperatura modificados de Petit et al., (1999), sedimentológicos de Ramos (2014).

Ao longo desta seção estratigráfica os sedimentos são muito pobremente selecionados. A assimetria muito negativa das amostras aponta para a ocorrência de mecanismos de transporte de características e magnitudes diferenciadas. O nível estratigráfico superior apresenta estrutura laminada, que aponta para uma remobilização apenas superficial dos sedimentos; curtose platicúrtica e distribuição granulométrica polimodal (RAMOS, 2014). Já o nível inferior aponta para ocorrência de fluxos de lama não canalizados, que potencialmente removeram os mantos de intemperismo das áreas fontes a maiores profundidades.

Ramos (2014) analisou os sedimentos morfoscopicamente, no mesmo local do presente estudo e identificou que os sedimentos são heterogêneos, sendo a maior parte do material (> 60\%) sub-discoidal e sub-prismoidal, indicando uma baixa variabilidade dos modos de transporte na encosta, além de proximidade da área fonte. Os grãos analisados derivam, portanto, do intemperismo da rocha in situ, e sua morfologia é em grande parte herdada da fábrica original.

A composição mineralógica dos sedimentos traduz aspectos provenientes diretamente das alteritas que os originaram; sobretudo pela presença de fragmentos de rocha e pedorrelíquias ferruginosas, assim como visto na Área 01. A presença de argila formando agregados no depósito pode estar relacionada ao ambiente de encosta, no qual ocorre migração das frações mais finas em meio aquoso para base do relevo, como observado no Planalto Sedimentar do Araripe por Lima (2015).

Ao longo da seção estratigráfica da Área 02 as idades dos sedimentos variaram entre $2.300 \pm 410$ (unidade basal) e $465 \pm 80$ anos A.P. (unidade superior), corroborando a ocorrência de eventos de maior torrencialidade no Holoceno superior. A idade basal de aproximadamente 2.300 anos A.P. pode ser correlacionada ao mesmo episódio desencadeador de transporte coluvial ocorrido na área de estudo a $2.100 \pm 350$ anos A.P., conforme identificado por Tavares (2015) a sudeste do Maciço e a leste do Planalto da Borborema, em Brejo da Madre de Deus-PE segundo demostrado por Silva (2013), que identificou depósito coluvial com $2.550 \pm 470$ anos A.P. A sobreposição temporal desses eventos aponta para a ocorrência de eventos 
formativos de características estocásticas, circunscritos aos compartimentos de cimeira da Borborema, e sem repercussão similar em outros setores da região.

Não obstante, fora do domínio das encostas, Mutzenberg (2010) e Lira (2014) identificaram depósitos de leques e planícies aluviais, respectivamente, dentro do intervalo de 2.000 a 2.500 anos A.P., para a Serra da Capivara-PI e sub-médio São Francisco-PE. Neste último contexto, Lira (2014) encontrou depósitos eólicos de até 1.700 A.P., como indício de momentos mais secos. É importante observar, que a fase de coluvionamento ocorrida a 2.300 anos A.P., circunscrita aos setores elevados a leste do Planalto da Borborema, apesar de regionalmente restrita, também pode ter sido sincrônica a fases frias do Paleo-ENOS (CONROY et al., 2008; MOY et al., 2002; STAINES-URÍAS et al., 2015), que contemporaneamente repercutem sobre o Nordeste oriental com sensível aumento das precipitações.

Outro evento estocástico identificado na área refere-se ao depósito de lama arenosa datado de 465 anos A.P. o qual, se for levado em consideração a escala de erro da idade, pode estar relacionado às modificações climáticas da Pequena Idade do Gelo. Sobre as encostas do Maciço da Serra da Baixa Verde e do Planalto da Borborema não foram ainda identificados outros sedimentos coluviais deste período.

Em uma escala global, as idades encontradas correspondem à fase final do último Evento Bond com redução térmica brusca de $-1,08^{\circ} \mathrm{C}$ (PETIT et al., 1999), e migração meridional mais marcada da Zona de Convergência Intertropical (HAUG et al., 2001). Na América do Sul este momento corresponde a episódio mais intenso da fase fria do ENOS (MOY et al., 2002; CONROY et al., 2008). Localmente, evidências morfoestratigráficas apontam para ocorrência de ruídos sobre mecanismos desencadeadores da sedimentação de encosta, que assim fogem aos padrões regionais e globais, evidenciando o papel do relevo local sobre a indução dos eventos erosivo-deposicionais, atuando em escalas iguais ou menores que $10^{2}$ anos.

\section{3. Área 03}

Localizada em uma encosta com cobertura coluvial com 500m de comprimento, declividade média de $16,3 \%$, morfologia côncava na forma de anfiteatro aberto e seccionada por voçorocas. O depósito estruturado em rampa coluvial apresenta espessura total de três metros. Todo o pacote sedimentar exibe uma estrutura maciça, sem estratificação, composta de areia fina e coloração vermelho-amarelada em razão da concentração de óxidos de ferro e alumínio. As coletas para datação foram realizadas da base para o topo, nas seguintes profundidades: 10, 90, 156 e 230 centímetros (Figura 4).

Os sedimentos analisados neste setor apresentam-se muito pobremente selecionados e com assimetria muito negativa. Assim como nas demais áreas de coleta, os valores de assimetria apontam para ação de fluxos de transporte de características e magnitudes distintas, operando a curta distância da área fonte do material. Este, por sua vez, provém da remoção das alteritas in situ situadas nos setores mais elevados da encosta. A curtose platicúrtica e distribuição polimodal das amostras também refletem que as áreas-fontes se situam nas proximidades dos loci deposicionais.

Nesta área de coleta não foram observados fluxos de detritos e clastos na fração cascalho o que aponta para uma remobilização apenas superficial dos mantos de alteração à montante, provavelmente sem chegar a atingir a frente de intemperismo. Deve-se considerar também que a vegetação possivelmente desempenhou papel significativo sobre o escoamento superficial, inibindo o destacamento mais eficaz dos sedimentos em profundidade. Os depósitos de corridas de lama, por seu turno, indicam vigência de processos superficiais de grande torrencialidade com hidrodinâmica alta, dominada por fluxos não canalizados.

Ao analisar o mesmo colúvio, Ramos (2014) identificou na fração $250 \mu \mathrm{m}$ uma grande heterogeneidade morfológica, alto grau de esfericidade, e baixo grau de arredondamento. Essas características refletem a ação de mecanismos de transporte constantes, por fluxo de lama, e proximidade das áreas fontes. Conclui-se que os grãos devem sua forma a padrões herdados da rocha-mãe com poucos sinais de abrasão decorrentes do arrasto ao longo da encosta. Mineralogicamente as amostras analisadas apresentam características em comum com as áreas de coleta 1 e 2, com predomínio de aspectos herdados da rocha mãe, com mistura de minerais primários, oriundos da alterita desenvolvida sobre o sienito, com aqueles do ciclo supérgeno neoformados em ambiente tropical sub-úmido.

Os níveis estratigráficos que compõem o depósito coluvial da área de amostragem 03 remontam da transição Pleistoceno/Holoceno ao Holoceno Médio, apresentando os seguintes níveis datados: $11.700 \pm 2.060,5.700 \pm 1.050$ e $5.300 \pm 880$ anos A.P. Dentre todas as áreas investigadas nesta pesquisa, essa foi a que resultou em sedimentos mais antigos, datados do limiar inferior do Holoceno. Este momento coincide com o ajuste das paisagens tropicais às condições de temperatura mais elevada e maior pluviometria, que resultou em ubíqua deposição coluvial ao longo do cinturão tropical do globo (ERIKSSON 
et al., 2000). De acordo com a curva de paleo-temperaturas para o Hemisfério Sul (PETIT et al., 1999) a variação entre o nível basal e o topo desta seção estratigráfica, ou seja entre o limiar Pleistoceno/Holoceno e o Holoceno médio, pode haver alcançado quase $2^{\circ} \mathrm{C}$.

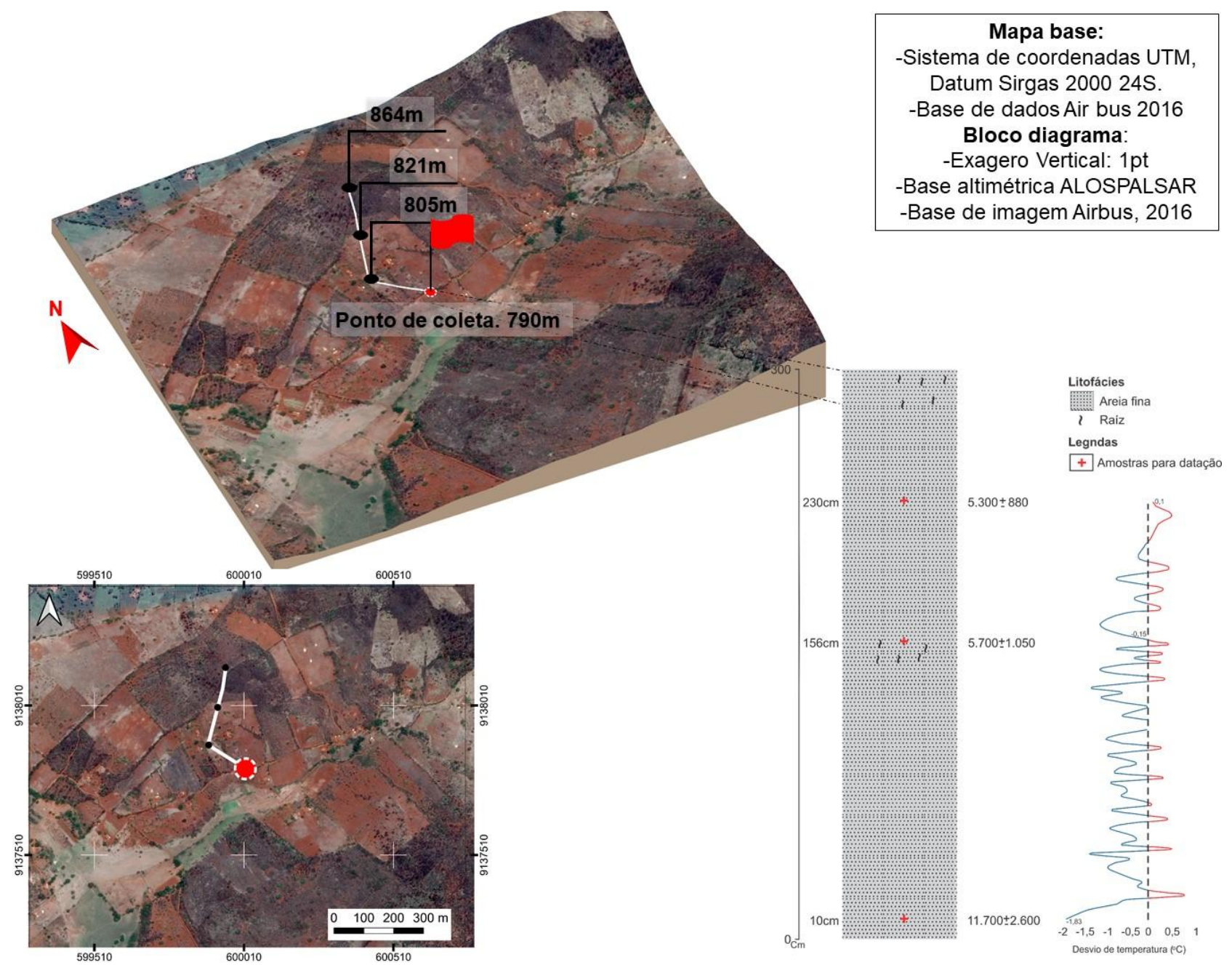

Figura 4: Encosta na forma de anfiteatro com cobertura coluvial e perfil vertical da seção estratigráfica com indicação das idades e os desvios de paleotemperatura. Fontes: dados de paleotemperatura modificados de Petit et al., (1999), sedimentológicos de Ramos (2014).

$\mathrm{Na}$ área de estudo, os depósitos coluviais holocênicos mais antigos apresentaram idades variando entre $11.700 \pm 2.060$ e $11.300 \pm 1.400$ anos A.P. para o trabalho de Tavares (2015), enquanto que a contribuição de Corrêa (2001) apontou para 10.600 \pm 2.600 anos A.P. Na Serra da Capivara-PI, Mutzenberg (2010) registrou unidades deposicionais de origem aluvial datadas de 11.700 anos A.P., ao passo que Gurgel et al., (2013), trabalhando no Maciço do Pereiro-RN, obtiveram idades de 11.750 e 11.500 anos A.P. para depósitos coluviais. No sub-médio São Francisco-PE, Lira (2014) registrou idade de 11.930 anos A.P. para depósitos da paleo-planície de inundação. Percebe-se, portanto, que no contexto regional do Nordeste semiárido a transição Pleistoceno/Holoceno foi marcada por inputs climáticos com energia suficiente para desencadear sedimentação de encosta generalizada e até mesmo expansão das planícies de inundação ao longo dos maiores cursos fluviais.

Esta fase é marcada globalmente pelo final do período denominado de Younger Dryas (12.800 - 11.500 anos AP) assim como pelo episódio Heinrich 0 (ADAMS et al., 1999). Trata-se de uma fase durante a qual a circulação atmosférica global passou por uma reconfiguração nos sistemas desencadeadores de chuva, com registro de precipitações torrenciais sobre os trópicos, cujas magnitudes ultrapassam em larga escala os eventos contemporâneos, com importantes implicações sobre a morfogênese e formação de modelados de agradação.

O nível estratigráfico datado de 5.700 \pm 1.050 anos A.P. reflete um evento deposicional ocorrido durante o Optimum Climático, um momento já reconhecidamente mais úmido na região. Esse episódio de sedimentação holocênico também foi encontrado por Tavares (2015) com sedimentos coluviais com idade de 
5.850 \pm 900 anos A.P. Igualmente, Corrêa (2001) identificou uma fase ativa de coluvionamento no Maciço entre 6.300 e 6.900 A.P. No contexto do Nordeste semiárido, colúvios do Holoceno Médio foram registrados no Maciço do Pereiro-RN (GURGEL et al., 2013), ao passo que Lira (2014) identificou depósitos de enchente no Sub-médio São Francisco-PE para o mesmo período. Autores como Moy et al. (2002); Conroy et al. (2008) e Staines-Urías et al. (2015) atribuem a maior precipitação neste período à transição brusca entre uma fase quente do Paleo-ENOS e uma fase fria.

Fluxos de lama com idade de 5.300 \pm 880 anos A.P., representam a unidade deposicional mais jovem dessa área de coleta, e possivelmente refletem episódios de transporte das camadas mais superficiais do solo durante ação de chuvas torrenciais. No âmbito do Maciço da Serra da Baixa Verde, Tavares (2015) registrou a ocorrência de um colúvio com idade de 5.200ะ730 A.P., correlato à unidade supramencionada. Sob o ponto de vista da temperatura no Hemisfério Sul, esse momento reflete um desvio positivo de $+0,1^{\circ} \mathrm{C}$, (PETIT et al., 1999).

No core semiárido do Nordeste não ocorrem depósitos de encosta do mesmo período, ainda que Lira (2015) tenha registrado episódios de remobilização eólica a 5.000 anos A.P., marcando momentos de secura severa na região. Assume-se, portanto, que a ocorrência dessas formas de agradação em níveis topográficos elevados, sobre as superfícies de cimeira regionais, apontem para o efeito localizado da orografia sobre os sistemas causadores de precipitação, intensificando-os.

\section{4. Área 04}

Localizada na transição entre condições úmidas da cimeira e semiaridez da Depressão Sertaneja, o local de coleta é formado por uma encosta recoberta por colúvio no formato de ombreira separando duas superfícies pedimentares. A seção vertical do ponto de coleta apresenta características distintas das demais áreas, no que tange os aspectos estratigráficos, granulométricos. Da base para o topo da seção, sobreposta ao regolito, repousa uma cascalheira, matriz suportada, com blocos angulosos que sugere a ocorrência de um paleopavimento inumado, formado pela evacuação seletiva das frações mais finas e concentração de cascalho. Acima da cascalheira ocorre uma camada de colúvio formada por uma areia média com grânulos, e entre 60 e 70 centímetros de profundidade ocorre uma camada de areia grossa. As camadas acima descritas apresentam descontinuidades verticais bem definidas em campo, podendo indicar discordâncias erosivas (Figura 5).

Nesta área de coleta os sedimentos são muito pobremente selecionados e apresentam assimetrias diferenciadas. A $35 \mathrm{~cm}$ da superfície a curva de distribuição é praticamente simétrica, ao passo que a $65 \mathrm{~cm}$ observa-se curva com assimetria muito positiva. A curtose resultou muito platicúrtica, o que evidencia o transporte a curta distância. Essas propriedades ainda indicam que a energia dos processos superficiais ocorridos na área não favoreceu a erosão do regolito em níveis mais profundos. A classificação do material em areia lamosa, aponta também para ação do clima semiárido sobre alteração geoquímica, com baixo teor de argila, além de indicar as corridas de lama não canalizadas como principal mecanismo de transporte na encosta.

Os dados sedimentológicos sugerem que as premissas propostas por Corrêa (2004), Silva (2013) e Melo (2008) no que diz respeito à interferência das alteritas formadas em ambiente semiárido sobre a oferta de material para erosão se confirmam na área de estudo. Os autores também apontam para a ação de processos de hidrodinâmica elevada e pulsátil na remoção do material, que são corroborados por meio da aplicação dos diagramas de Pejrup (1988) aos sedimentos analisados.

Ao analisar a fração $250 \mu \mathrm{m}$ do mesmo colúvio, Ramos (2014) identificou a heterogeneidade morfológica do material e valores de esfericidade menores que 50\%, nitidamente mais baixos que nas outras áreas amostradas. $\mathrm{O}$ grau de arredondamento também se mostrou bastante diferenciado, com predomínio, mais de $90 \%$, de grãos angulosos a muito angulosos.

As características dos sedimentos indicam uma continuidade dos processos de transporte, com predomínio dos fluxos de lama a curta distância da área fonte. Desta maneira, a forma dos grãos é substancialmente herdada das alteritas in situ, com pouca alteração desenvolvida durante o processo de arrasto sobre a superfície da encosta. Em comparação com os demais pontos estudados, os sedimentos apresentam características mais marcadamente oriundas dos processos de alteração da rocha-mãe sob condições semiáridas. 


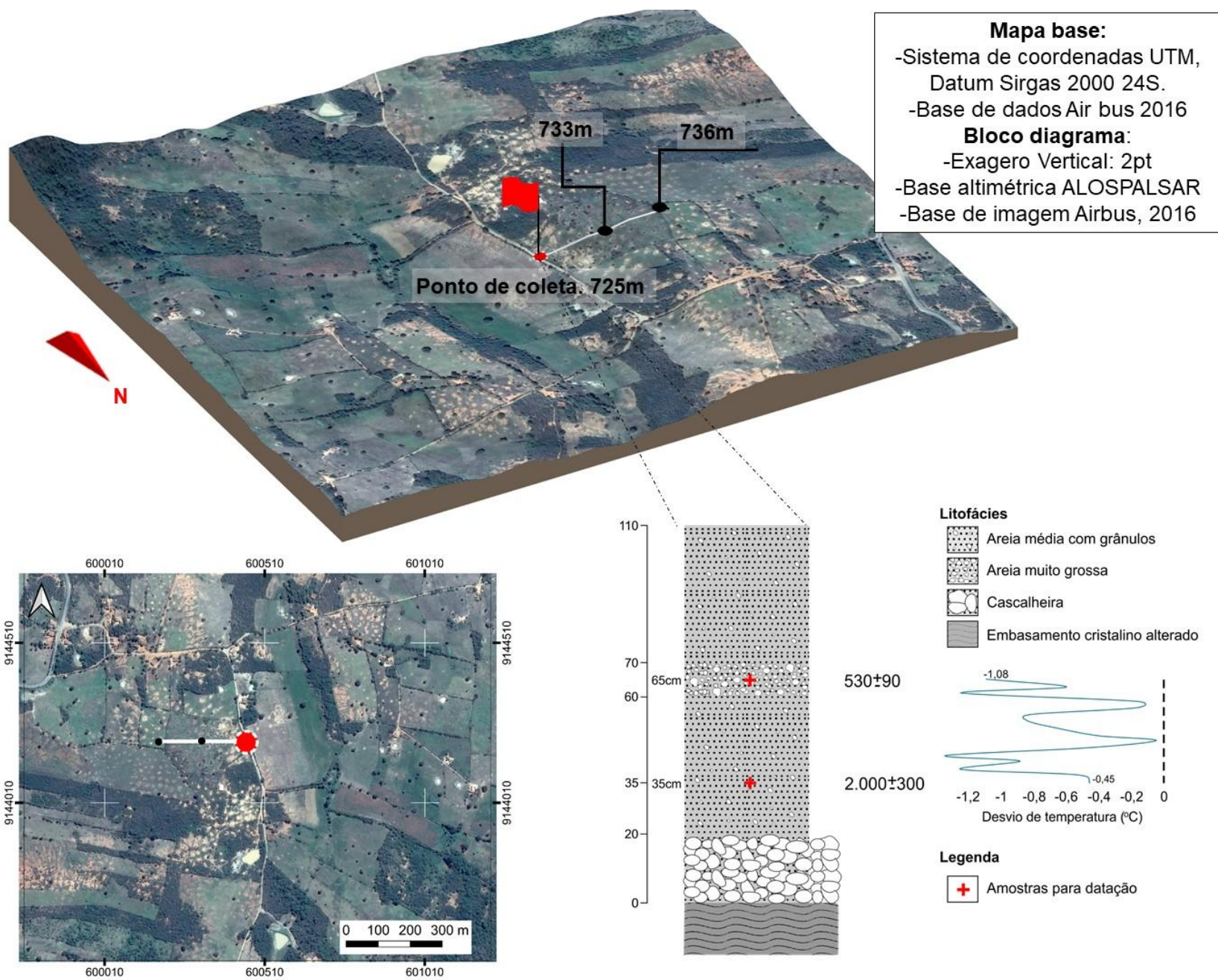

Figura 5: Bloco diagrama com seção estratigráfica do colúvio da área 4, com indicação das idades e os desvios de paleotemperatura para cada idade.Fontes: dados de paleotemperatura modificados de Petit et al., (1999), sedimentológicos de Ramos (2014).

Os dados de datação deste depósito de colúvio registram a operação de corridas de lama sob regimes torrenciais no Holoceno Superior, com idades variando entre $2.000 \pm 300$ e $530 \pm 90$ anos A.P. As duas unidades estratigráficas submetidas a datação foram depositadas em períodos com desvio negativo da temperatura global, variando entre $-0,45^{\circ} \mathrm{C}$ para a unidade mais antiga e $-1,08^{\circ} \mathrm{C}$ para a unidade mais jovem.

A unidade mais antiga, com idade de 2.000 anos A.P., trata-se de areia lamosa, derivada dos eventos torrenciais espasmódicos do Holoceno Superior. Tavares (2015) também identificou materiais cronocorrelatos para outros pontos do Maciço, com idade de $2.100 \pm 350$ anos A.P. No âmbito do core semiárido do Nordeste, como já enunciado acima na descrição da Área 01, a única área onde se encontram sedimentos de encosta da mesma idade é no Maciço do Pereiro-RN (GURGEL et al., 2013). Em seguida a esta fase mais úmida, Lira (2014) no sub-médio São Francisco encontrou evidências de retrabalhamento eólico de depósitos dunares a 1.700 anos A.P.

Haug et al. (2001) apontam para que o período em questão é marcado por grande variação na posição meridional da ZCIT, marcando momento de passagem entre dois eventos Bond e um episódio de decréscimo brusco da temperatura da ordem $-1,08^{\circ} \mathrm{C}$ (PETIT et al., 1999). Regionalmente, tem-se o efeito da alternância abrupta entre fases frias e quentes de Paleo-ENOS (MOY et al., 2002; CONROY et al., 2008). Localmente, aventa-se ainda a interferência dos relevos mais altos da Borborema sobre a redinamização das massas de ar, provocando chuvas localizadas.

O depósito lamoso datado de 530 anos A.P., levando-se em consideração a margem de erro da datação, pode estar relacionado às alterações climáticas decorrentes da Pequena Idade do Gelo, sendo, portanto, crono-correlato à amostra datada na Área 02 com idade de 465 anos AP. No semiárido nordestino, Lira (2014) também registrou a ocorrência de sedimentos fluviais com idade aproximada de 450 anos AP.

Globalmente estes episódios de sedimentação ocorrem em proximidade ao último Evento Bond, que resultou em um rebaixamento geral da temperatura de $-1,08^{\circ} \mathrm{C}$, de acordo com a curva de Petit et al., (1999) 
para o Hemisfério Sul. Da mesma forma, este momento é marcado por uma migração para o sul da ZCIT, conforme nos apontam Haug et al., (2001). Na América do Sul, prováveis mecanismos propulsores da sedimentação de encosta podem ter sido dinamizados por um pico de fase fria do ENOS (MOY et al., 2002; CONROY et al., 2008).

\section{Considerações finais}

O maciço da Serra da Baixa Verde, assim como outros maciços estruturais que se elevam dentro do core semiárido nordestino, corresponde a uma área chave para os estudos da dinâmica geomorfológica e paleoambiental quaternária na região. A remobilização dos mantos de intemperismo, mais espessos que os do entorno em função da maior disponibilidade hídrica, resulta na acumulação de depósitos de encosta e fluviais cujas características estratigráficas, composicionais e geocronológicas apontam para um controle dos condicionantes climáticos sobre a morfogênese. Não obstante, observa-se uma acoplagem hierárquica das formas em função da magnitude dos eventos desencadeadores responsáveis pelo cruzamento de patamares formativos que resultam efetivamente na deposição das unidades agradacionais. No caso da área de estudo, os depósitos refletem controles climáticos operantes em escala global, regional e local, estando os dois últimos mais relacionados a possíveis paleo-tele-conexões com fenômenos da circulação secundária da América do Sul como os paleo-ENOS.

Os depósitos estudados apresentaram-se confinados em intervalo de tempo que alcança desde o limiar Pleistoceno/Holoceno até a Pequena Idade do Gelo. Contudo, enquanto os depósitos resultantes da reumidificação geral observada ao final do Pleistoceno são ubíquos nas demais áreas do Nordeste semiárido, os depósitos do Holoceno médio e superior apontam para ocorrências mais localizadas, provavelmente relacionadas à ação de eventos pluviais orograficamente condicionados, mais intensos sobre o maciço mesmo quando o entorno semiárido da região restava sob o domínio de condições secas.

Desta forma constata-se que no caso dos brejos de altitude do Nordeste oriental os sedimentos de encosta representam de fato valiosos proxies paleo-climáticos, sobretudo diante da escassez de ambientes adequados à preservação de outros índices paleoambienais de origem vegetal como os grãos de pólen. Por outro lado, a análise das relações hierárquicas entre processos e formas permitiu constatar vínculo temporal e espacial entre a dimensão e frequência de ocorrência das unidades geomorfológicas e tipos de eventos climáticos responsáveis pela gênese, o que evidenciou a ocorrência de dimensões gradativamente mais localizadas à medida que os eventos formativos sejam controlados pela ação do relevo sobre os sistemas causadores de chuva.

\section{Referências}

ADAMS, J., MASLIN, M.; THOMAS, Ellen. Sudden climatic transitions during the Quaternary. Progress in Physical Geography, v. 23, 1999, p. 01-36.

AMORIM, R. de F. Integração entre dinâmicas geomorfológicas multitemporais no Planalto da Borborema, Semiárido do NE do Brasil. 2015. Tese (Doutorado em Geografia) - Programa de PósGraduação em Geografia, Universidade Federal de Pernambuco, Recife, 2015.

AMORIM, R. de F.; CORRÊA, A. C. de B. SILVA, D. G. da. Tempo e magnitude nos processos geomorfológicos. Revista de Geografia, Rio Claro, v. 41, n. 1, 2016, p. 17-31.

AITKEN, M. J. An introduction to optical dating: the dating of Quaternary sediments by the use of photostimulated luminescence. New York: Oxford University Press Inc., 1998. 267 p.

BEHLING, H.; LICHTE, M. 1997. Evidence of Dry and Cold Climatic Conditions at Glacial Times in Tropical Southeastern Brazil. Quaternary Research, v. 48, 1997, p. 348-58.

BIGARELLA, J.J.; ANDRADE-LIMA, D.; RIEHS, P.J. Considerações a respeito das mudanças paleoambientais na distribuição de algumas espécies vegetais e animais do Brasil. Anais da Academia Brasileira de Ciências, 47: 412-464, 1975.

CAMARGO FILHO, M.; BIGARELlA, J. J. Correlação de parâmetros estatísticos de sedimentos de vertentes, rampas de colúvio-alúvio e terraço de várzea da bacia do Bananas, Guarapuava - PR. Geosul, v. 14, 1998, p. 438-442. 
CONROY, J. L.; OVERPECK, J.T., COLE, J. E.; SHANAHAN, T.M.; STEINITZ-KANNAN, M. Holocene changes in eastern tropical Pacific climate inferred from a Galápagos lake sediment record. Quaternary Science Reviews, v. 27 n 11, 2008, p. 1166-1180.

CORRÊA, A. C. de B. Dinâmica geomorfológica dos compartimentos elevados do Planalto da Borborema, Nordeste do Brasil. 2001. Tese (Doutorado em Geografia) - Universidade Estadual Paulista, Rio Claro, 2001.

ERIKSSON, M.G.; OLLEY, J.M.; PAYTON, R. W. Soil erosion history in central Tanzania based on OSL dating of colluvial and alluvial hillslope deposits. Geomorphology, v. 36, 2000, p. 107-128.

LANCI, L.; HIRT, A. M. Evidence of Atlantic Multidecadal Oscillation in the magnetic properties of Alpine lakes during the last 2500 years. Palaeogeography, Palaeoclimatology, Palaeoecology, v. 440, 2015, p. 4752.

LIMA, F. J. de. Evolução geomorfológica e reconstrução paleoambiental do setor subúmido do Planalto Sedimentar do Araripe: um estudo a partir dos depósitos coluviais localizados nos municípios de Crato e Barbalha - Ceará. 2014. Tese (Doutorado em Geografia) - Programa de Pós-Graduação em Geografia, Universidade Federal de Pernambuco, Recife, 2014.

LIRA, D. R. de. Origem, dinâmica e reconstrução geomorfológica através da assinatura geoquímica dos latossolos nas bacias do Riacho do Pontal e GI-8. 2014. Tese (Doutorado em Geografia) - Programa de Pós-Graduação em Geografia, Universidade Federal de Pernambuco, Recife, 2014.

GURGEL, S. de P.; BEZERRA, F. H.R.; CORRÊA, A. C.B.; MARQUES, F. O.; MAIA, R. P. Cenozoic uplift and erosion of structural landforms in NE Brazil. Geomorphology, v. 186, 2013, p. 68-84.

HAUG, H.G.; HUGHEN, K. A.; SIGMAN, D.M.; PETERSON, L.C.; RÖHL, U. Southward migration of the Intertropical Convergence Zone through the Holocene. Science, v. 17, 2001, p. 1304-1308.

MELO, J. S. Dinâmica geomorfológica do ambiente de encosta em Brejo da Madre de Deus-PE: uma abordagem a partir da perspectiva morfoestratigráfica aos depósitos coluviais. 2008. Dissertação (Mestrado em Geografia) - Programa de Pós-Graduação em Geografia, Universidade Federal de Pernambuco, 2008.

MOURA, J. R. S.; MELLO, C. L. Classificação aloestratigráfica do Quaternário superior da região de Bnanal (SP/RJ). Revista Brasileira de Geociências, v. 21, 1991, p. 236-254.

MOURA, J. R. S.; SILVA, T. M. Complexo de rampas de colúvio. In: Cunha, S. N.; Guerra, A. J. T. Geomorfologia do Brasil, Bertrand Brasil, Rio de Janeiro, 1998, 338 p.

MOY, C. M.; SELTZER, G. O.; RODBELL, D. T.; ANDERSON, D. M. Variability of El Niño/Southern Oscillation activity at millennial timescales during the Holocene epoch. Nature, v. 420, 2002, p. 162-165.

MUTZENBERG, D. S. Ambientes de ocupação pré-histórica no boqueirão da pedra furada, Parque Nacional Serra da Capivara-PI. 2010. Tese (Doutorado em Arqueologia) - Programa de Pós-Graduação em Arqueologia, Universidade Federal de Pernambuco, 2010.

PAISANI, J. C.; PAISANI, S. D. L.; OSTERRIETH, M. L.; PONTELLI, M. E.; FUJITA, R. H. Dinâmica de rampa de colúvio na superfície de Palmas/Água Doce durante o Quaternário tardio - bases para compreender a evolução das encostas no Planalto das Araucárias. Revista Brasileira de Geomorfologia, v. 18, n. 4, p.103-116, 2017.

PEJRUP, M. The triangular diagram used for classification of estuarine sediments a new approach. In: BOER, P.L.; VAN GELDER, A.; NIO, S. D. (ed.). Tide-Influenced Sedimentary Environments and Facies. D. Reidel, Dordrencht. 1988. p. 289-300.

PETIT J. R. et al. Climate and atmospheric history of the past 420,000 years from the Vostok ice core, Antarctica. Nature, v. 399, 1999. 
RAMOS, Débora Albuquerque Meira Coelho. Os depósitos de encosta na reconstrução da dinâmica geomorfológica na bacia do riacho Piancozinho (Pernambuco/Paraíba). 2014. Dissertação (Mestrado em Geografia) - Programa de Pós-Graduação em Geografia, Universidade Federal de Pernambuco, Recife, 2014.

SELBY, M. J. Hillslope Matirials and processes. Oxford University Press. New York, USA, 1993. 445p.

STAINES-URÍAS, Francisca; GONZÁLEZ-YAJIMOVICH, O.; BEAUFORT, L. Reconstruction of past climate variability and ENSO-like fluctuations in the southern Gulf of California (Alfonso Basin) since the last glacial maximum. Quaternary Research, v. 83, 2015. p. 488-501.

SILVA, D. G. da. Reconstrução da dinâmica geomorfológica do semiárido brasileiro no Quaternário superior a partir de uma abordagem multiproxy. 2013. Tese (Doutorado em Geografia) - Programa de Pós-Graduação em Geografia, Universidade Federal de Pernambuco, Recife, 2013.

TAVARES, B. de A. C. Evolução morfotectônica dos pedimentos embutidos no Planalto da Borborema, Nordeste do Brasil. 2015. Tese (Doutorado em Geografia) - Programa de Pós-Graduação em Geografia, Universidade Federal de Pernambuco, Recife, 2015.

THOMAS, M. F. Landscape sensitivity to rapid environmental change - a Quaternary perspective with examples from tropical areas. Catena, v. 55, 2004, p. 107-124. 